\title{
Contents, Vol. 78, 1938
}

\section{Inhaltsverzeidinis.}

Originalarbeiten.

Seite

Bosnjakovíc, Srecko, Beitrag zur Sarkomentstehung auf Narbengewebe . 86

Cornel, M., Über Prurigo uratica 73

Cappelli, E., Tuberkulid vom Typus einer Folliculitis spinulosa decalvans des

Kapillitium mit diffuser Keratosis follicularis spinulosa 1

Dóczy, G., Wismutnachweis aus tierischen Organen nach dem Verfahren

von Bodnár-Karell unter besonderer Berücksichtigung des retikulo-endo-

thelialen Systems 82

Faragó, L·, siehe Vámos, L.

Feßler, Alfred, Benzpyrenepitheliom und Benzpyrensarcom bei der Maus . 329

Feítweis, E., Verbindung von Zahlen, geometrischen Figuren und Himmelsrichtungen mit geschlechtlichen und heilkundlichen Vorstellungen auf niederer Kulturstufe 260

Hoffmann, E., Über nicht venerische plastische Lymphangitis im Sulcus ccronarius penis mit umschriebenem Ödem 24

Hoffmann, E., I. Über eine einfache Schnellfärbung von Hautpilzen (Microsporon minutissimum) in Schuppen und Abklatschprãparaten solcher . 379 Hoffmann, E., II.

Über die allgemeine Anwendungsinöglichkeit der Azur-

eosínglyzerin-Tropfenfärbung auch an Paraffinschnitten und bei Der-

matovirosen 383

Kunewälder, E., und Oppenheim, M., Komplikationen der männlichen Gonor-

rhöe und ihre serologische Diagnostik (MOR.) 185

Kuske, H., lur Beurteilung der Luesreaktionen im Serum und im Liquor

cerebrospinalis bei Impfmalaria 137

Melchior, E., Ein Fall von parallergischem Impfexanthem 255

Melczer, N., Bullose, flächenhafte tiautentzündung im Frühstadium des

Lymphogranuloma inguinale 337

Melczer, N. und Sîpos, K., Übertragungsversuche der lymphogranulomatðsen Allergie 249

Oppenheim, M., siehe Kunewälder, E.

Robert, P., lur Kenntnis der Pyodermia chronica papillaris et exulcerans 198

Schlammadinger, ]., Über gedrehte Haare, Pili torti 206

Schnítzer, A., Vergleichende tierexperimentelle und klinische Untersuchungen

fiber die Sensibilisierbarkeit organischer Arsenpräparate mit besonderer

Berücksichtigung des Syntarsols 313

Sipos, K., siehe Melczer, N.

Szép, E., Die Wirkung von Hautextrakt auf die Agglutininbildung .... 27 
Urbach, E., lur Ätiologie des Lichen urticatus bzw. Strophulus infantum

auf Grundlage von 225 eigenen Fallen 77

Vámos, L. und Faragó, L., Die quantitative Änderung der Eosinophiie $\pi$ auf

Adrenalineínwirkung bei Pemphigus und ihre prognostische Bedeutung 145 Wiersema, M. U. siehe Zurhelle, E. Zurhelle, E. und Wiersema, M. U., Papulonekrotische Tuberkulide oder Pyodermien? 129

Sammelreferate.

Seite

Psoriasis, Lichenerkrankungen, Verhornungsanomalien, Pigmentanomalien, NagelundHaarerkrankungen, ErkrankungenderTalgdrüsenundSchweiß-

drüsen. (Anfang 1937 bis Anfang 1938.) Von H. O. Loos-Innsbruck . 33

Gutartige und bösartige Tumoren nebst Naevi. Von /. Wendlberger-Graz 95

Strahlenheilkunde. Von Philipp $\Lambda 7 / 8 / /$ er-Aachen 151

Dermatomykosen. Von Th. Preininger-Oebrecen 212

Die Hauttuberkulose. Von R. V $3 / 4^{1 / 2}$-Wien 272

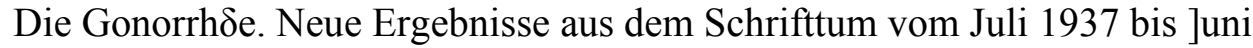

1938. Von A. Feßler-Wien 347

Lepra. Von R. Vo $1 / 2$-Wien 389

Syphilis. Referat über die Arbeiten des Jahres 1937. Von W. Güdel-Bern 403

Übrige venerische Krankheiten, Bekãmpfungder Geschlechtskrankheiten, Sexual-

wissenschaft. Übersicht über das Schrifttum vom November 1937 bis

Oktober 1938. Von F. S. Nohara-Bonn 417

Gesellschaftsberichte.

Société Française de Dermatologie et de Syphiligraphie

Sitzung vom 10. Juni $1937 \quad 64$

Sítzung vom 8. Juli $1937 \quad 118$

Sitzung vom 4. November $1937 \quad 173$

Sitzung vom 9. Dezember $1937 \quad 178$

Sitzung vom 13. Januar $1938 \quad 242$

Sitzung vom 13. Februar $1938 \quad 368$

Sitzung vom 13. März $1938 \quad 373$

Royal Society of Medicine, Section of Dermatology

Sitzung vom 21. Oktober $1937 \quad 68$

Sitzung vom 18. November $1937 \quad 122$

Sitzung vom 16. Dezember $1937 \quad 238$

Sitzung vom 20. Januar $1938 \quad 241$

North of England Dermatologicai Society

Jahrestagung vom 22. Oktober 1937 in Manchester 71

Sitzung vom 9. Dezember 1937 in Edinburgh 183

104. Sitzung der Nederlaná $3 / 8$ che Vereeniging van Dermatologen am 24 . und

25. April 1937 in Groningen

Therapeutîsches in der Literatur

269

Bemerkenswerte Krankenbeobachíungen.

Arzt- und Berufsinfektion, zwei frühgehcilte, lange beobachtete Erkrankungen.

Von Erich Hoffmann-Bonn

62

Jahrelange, immer wiederholte Neosilbersalvarsan-Behandlung alter erschei- 
nungsloser Spâtsyphilis. Von Erich Hoffmann-Bonn

An Erich Hoffmann .

377

Jean Darier $\dagger$

125

Sahachiro Hata $\dagger$

456

Buchbesprechungen 71, 126,

246

Perso $\pi$ alien und Tagesnachrichten $72,128,183,248,312,376,456$ 